УДК 94 (47).084.8

\title{
РАЗВИТИЕ ГОРОДОВ СТАВРОПОЛЬЯ В 1960-е ГОДЫ: ПРОБЛЕМЫ ПОЗДНЕЙ УРБАНИЗАЦИИ
}

Данная статья посвящена истории городов Ставрополья в 1960-е гг. Основополагающим фактором, повлиявшим на социальное и культурное состояние городского населения региона, была урбанизация, которая стала результатом комплекса миграционных, градостроительных процессов, изменений в социальной структуре общества, городской культуре и образе жизни. В силу своей сельскохозяйственной специфики Ставропольский край в данный хронологический период только стал на путь модернизации и урбанизации, которые повлекли за собой социокультурные изменения.

На общероссийском фоне середины XX века города Ставрополья были слабо урбанизированными, несмотря на быстрый рост городского населения и высокую концентрацию нового промышленного строительства в них. В то же время, хотя и медленно, с большими трудностями, начался процесс смены хозяйственных занятий горожан - увеличилась доля населения, занятых в сфере управления, культуры, обслуживании, появились признаки перехода к промышленному труду. На территории края проводилась масштабная работа по укрупнению предприятий химической, газовой, нефтяной и электротехнической отраслей. Без внимания не остались и предприятия легкой промышленности. Это не могло не ока- зать существенное впияние на структуру миграционных процессов. Также в процессе урбанизации происходило взаимопроникновение городского и сельского пространства, постепенная интеграция и смешение бытовых и культурных границ, унификации досуга городских и сельских обывателей в рамках социальной политики советской власти

Город, в условиях урбанизационного перехода, сохраняет и приумножает свой потенциал в организации жизнедеятельности всего общества и становится не только носителем новых идей, возможностей, объединяющих жителей, выразителем социальных потребностей, но и средством перехода к исторически новому состоянию.

Проблема, поднятая в данной статье, актуальна, так как исторический опыт становления нового социокультурного облика человека в различных социальных уровнях позднего советского социума позволяет увидеть и определить многие важные аспекты организации современного общества, находящегося на стадии перехода к новым формам общественной и культурной интеграции.

Ключевые слова: Северный Кавказ, социокультурный, региональная и локальная специфика, общенациональные тенденции, урбанизация.

\section{E. I. Pyrkina}

\section{DEVELOPMENT OF CITIES IN STAVROPOL KRAI IN THE 1960s: PROBLEMS OF LATE URBANIZATION}

This article is devoted to the development of cities in Stavropol in the 1960s. The underlying factor that influenced the social and cultural development of the urban population was urbanization, which was the result of a set of interrelated migration, urban planning processes, changes in the social structure of society, urban culture and lifestyle. Due to its agricultural specifics, the Stavropol Krai in this chronological period only took the path of modernization and urbanization, which resulted in sociocultural changes.

On the all-Russian background of the mid-twentieth century, the cities of Stavropol were poorly urbanized, despite the rapid growth of the urban population and the high concentration of new industrial construction in them. At the same time, albeit slowly, with great difficulty, the process of changing the economic activities of the townspeople began - the proportion of the population engaged in management, culture, and maintenance increased, and signs of a shift to industrial work appeared. On the territory of the region, large-scale work was carried out to consolidate the enterprises of the chemical, gas, oil and electrical industries. Light industry enterprises were not left without attention either. This could not have a significant impact on the structure of migration processes. The process of urbanization featured interpenetration of urban and rural space, the gradual integration and mixing of household and cultural boundaries, the unification of leisure time of urban and rural inhabitants in the framework of the social policy of the Soviet government.

The city, in the context of urban transition, retains and multiplies its potential in organizing the life activity of the whole society and becomes not only a carrier of new ideas and opportunities that unite residents, a spokesman for social needs, but also a means of transition to a historically new state.

The problem raised in this article is relevant, as the historical experience of the formation of a new socio-cultural image of a person in different social levels of the late Soviet society allows us to see and define many important aspects of the organization of modern society, which is at the stage of transition to new forms of social and cultural integration.

Key words: North Caucasus, socio-cultural, regional and local specificity, national trends, urbanization. 
Вопросы урбанизации и процессов ее сопровождающих занимают важное место среди ключевых проблем исторической науки. Для понимания сути современной российской модернизации и урбанизации важен анализ развития городов Ставрополья в 1960-е гт. Исследование нового облика человека в контексте опыта его исторического формирования на разных этапах развития советского общества дает возможность понять начала организации современного общества, в том числе специфику его движения к новым социально-культурным формам единства.

Изучение развития и роста городов подразумевает системное отражение общественных процессов, протекающих в основных ссрерах жизни города: политика, экономика, культура Выявление особенностей изменений структуры городского населения невозможно без анализа жизни города в указанных сферах. Вместе с тем, среди ключевых факторов выступает локальная особенность Ставрополья - его аграрная специфика. Следует помнить, любое местное сообщество подчиняется и общим тенденциям истории страны, так как является неотьемлемой частью общенационального пространства.

Целью данной работы стало изучение особенностей общественного, культурного и экономического развития городов Ставрополья в 60-егг. ХХ в. в контексте процесса урбанизации, как ведущего процесса в развитии городов. Исследование истории городов на Ставрополье через призму социально-культурных сфер жизни общества позволяет «раскрыть сущность города как локального социального сообщества через его становление, развитие оппозиции города и деревни центра и периферии, промышленных и аграрных секторов во всех их конкретно-исторических форMax» $[13$, c. 3].

Одной из теоретических проблем темы является определение категории «урбанизация». Рассмотрим наиболее часто используемые исследователями варианты. А. С. Сенявский, заложивший основы исторической урбанистики, в своем труде «Урбанизация России в XX в.: роль в историческом процессе» дает следующее емкое определение: «Урбанизация - это территориальная концентрация человеческой жизнедеятельности, ведущая к её интенсификации и диффференциации, вплоть до выделения новых её видов, обуславливающая формирование городских форм и пространственных структур расселения и распространения городского образа жизни» $[14$, с. 28] Согласно трактовке словаря иностранных слов, урбанизация - это и есть "сосредоточение населения и экономической жизни в крупных городах» $[10$, c. 187]. Урбанизацию можно определить как переход из сельского в городское состояние, сопровождавшийся ростом городов и городского населения или как «урбанизационный переход» [14 с. 35]. Характеризуется такой «переход» изменениями социально-классовой структуры общества, образа жизни, менталитета, формами проведения досуга, также системой расселения людей и размещения промышленных предприятий.
Урбанизационные процессы, происходившие в советской России, разработаны в историографии недостаточно глубоко. Особенно поверхностно исследована история провинциальных городов. Однако, имеющаяся литература позволяет сделать общие выводы о ставропольской урбанизации 1950-1960-х гг., здесь продолжали действовать, несмотря на советскую специфику, тенденции как «протоурбанизации», так и собственно урбанизации [1, с. 171]. Урбанизацию в советскую эпоху можно определить как «источник прорыва к новым формам общественной жизни, а также как мощный механизм, стимулировавший ломку традиционных структур, старых элементов городской жизни и городской культуры, перестройку образа жизни и форм социально-экономической организации всего общества на городской лад» [1, с. 173].

О начавшемся в 1960-е гг. урбанизационном ростеСтаврополья говорить сложно, в силу того, что впервые послевоенные десятилетия основ развития городов практически не наблюдались. Наличие обширной промышленной базы ещё не означало, что население Ставропольского края, в частности города Ставрополя, стало превращаться в городское общество. Впервые послевоенные десятилетия он оставался преимущественно аграрным городом. Несмотря на начавшееся повсеместное строительство, и интенсивное развитие промышленности, развитие культурной и духовной ссрер общества, ставропольчане не могли идентифицировать себя с представителями городского населения. Это объясняется тем, что более привычный образ жизни не мог быстро измениться, хотя наличие модной одежды, относительной доступности предметов быта не могли не оставить след. Более того, удельный вес населения города к 1960 г. значительно увеличился за счёт сельских жителей окрестных сёл, что способствовало повышению объёмов промышленного строительства

Следует учитывать, что урбанизация носила дуалистический характер: с одной стороны, протекали формально-статусные и социально-демографические изменения, а с другой, менялся внутренний мира человека [6]. Перемещение из сельской местности в городскую среду, в иную социальную категорию, пусть даже более высокую, редко превращало бывшего сельского обывателя в полноценного горожанина. Пребывание индивида в новом статусе носило искусственный характер, так как сознание отдельного взятого человека не могло быстро трансфрормироваться, как этого требовал на тот момент урбанизационный процесс.

Это связано с тем, что в переходной стадии урбанизационного процесса, которая в стране приходится, по мнению А. С. Сенявского на 19601980-е гг. горожане в большинстве своём несли на себе отголоски сельского менталитета, хотя относительно приспособленного к городским условиям. Ппоэтому мы можем сделать вывод, что урбанизация в советской России проходила под знаком превалирования полусельского мировос- 
приятия, мышления, изменением старых городов и становлением абсолютно новых, а также постепенным появлением новой культуры и образом жизни населения. Следовательно, процесс урбанизации оценивается не только через образ жизни населения городов, но и количественными показателями, такими как размер и численность городов, а также динамикой увеличения численности населения, проживающего в них [7]. Однако это лишь часть урбанизации, в которую органически входят специфическая эволюция социальной, культурной жизни горожан, их психологии.

Достаточно часто понятие урбанизации советского города отождествляется в исторической литературе с понятием индустриализации. Нет возражения, что важнейшими факторами урбанизации являются индустриализация, аграрно-промышленная интеграция и научно-техническая революция, сущностная сфера которых есть развёртывание отношений между человеком и природой. Индустриализация в любой исторический период требовала концентрацию материальных и трудовых ресурсов в городах.

В 1960-1970-е гг. Ставропольский край, как и другие аграрные регионы, переживал пик промышленного развития. На территории края развернулся новый этап индустриализации и урбанизации, которые втянули местное население в орбиту новых социальных отношений. Общий подъем социального и экономического потенциала СССР в 1960-х и 1970-х гг. определил фундаментальные вехи модернизации промышленности на Северном Кавказе. Во многом начавшийся рост был обусловлен стремлением реформировать организационно-управленческие основы общественного производства, а также выстроить приоритеты в направлениях социальной политики государства.

На Ставрополье активно проводилась специализация и концентрация промышленных предприятий. К 1960 г. в крае уже действовали 6 машиностроительных заводов, а к концу десятилетия в эксплуатацию были введены еще 7 предприятий данного профиля. В 1970-е гг. ведущую роль в крае стала занимать электротехническая отрасль. Особое внимание советского руководства было направлено на концентрацию производства предприятий химической, нефтегазовой и электротехнической отраслей, расположенных на территории Северного Кавказа [1, с. 171]. Легкая промышленность тоже не осталась без внимания. Были созданы «швейные объединения «Машук» в Пятигорске и Ставропольское мебельное объединение по производству кухонной мебели» $[1$, с. 174].

Одним из приоритетных направлений советской власти было развитие химической промышленности. На Ставрополье развернулось широкое строительство предприятий химической отрасли. Так, например, в 1957 г. был разработан проект планировки города Невинномысск, который изначально строился как промышленный центр, а если быть точнее, как промышленная пригородная зона города Ставрополя. Позже в проект были внесены поправки, которые предусматривали развитие города Невинномысска как «административного и культурного центра Невинномысского района с увеличением численности населении с 35 тыс. до 75 тыс. человек» [3, с. 2]. Все же приоритетным направление в деятельности города было развитие промышленности. Согласно проекту, в 1963 г. в городе стало функционировать крупнейшее на юге СССР предприятие большой химии Невинномысское объединение (Азот). В 1966 г. в Ставрополе первую химическую продукцию выпустил Ставропольский завод химических реактивов. К 1970 г. объем химической продукции в крае увеличился на $9 \%$. $[11$, с. 106].

Рост промышленных предприятий в регионе вызвал миграционные изменения. Перемещение жителей из села в город, привело к повышению уровня социальной мобильности населения. В город направлялись за поиском новой работы, прежде всего, в промышленных отраслях; молодежь за получением профессионального образования, так как города стали вузовскими центрами. По данным переписи населения 1959 г. доля городского населения в Ставропольском крае составила 31,2 \%. В целом по РСФСР в данный период доля городского населения была приблизительно 52-53\%. Ставропольский показатель оказался гораздо ниже, так как урабанизационный процесс начался позже, чем в других регионах. Но уже перепись 1970 г. показала значительный прирост городского населения - на $22 \%$.

В данных исторический период в крае наблюдается активная трансформация сельских поселений, которые сократились почти на $50 \%$. Такое значительное сокращение количества сельских населенных пунктов произошло, прежде всего, за счет ликвидации небольших населенных пунктов с численностью до 50 человек $[14$, с. 85]. В середине 1960-х гг. сельские жители переселялись в пригородные районы. Огромный миграционный поток населения хлынул из центральных и восточных районов Ставрополья, связано это было с неблагоприятными климатическими условиями.

В 1960-х гг. в процессе урбанизации на Ставрополье городская культура все активнее стала приникать в сельскую повседневность. Особые черты городского семейного быта прослеживались в домах сельских обывателей, например, наличие личных автомобилей, городской мебели, бытовой техники. Менялась мода и манеры поведения сельского населения, особенно молодежи. Труженики сельской местности свой досуг стали чаще строить по городскому типу: посещение кинотеатров, библиотек, театров, филармоний, кружков по интересам и других общественных мест.

Излюбленным местом проведения досуга были кинотеатры. В кино ходили семьями, профессиональными коллективами, школьными классами. Для зрителей кинематограф выполнял функцию второй действительности, так как зритель примерял на себя роль главного героя, вместе с ним переживал какое-либо событие. 
Такая форма проведения досуга была невероятно притягательной, так как позволяла зрителю оторваться от насущных проблем и пару часов отдохнуть. Клубные учреждения ставропольских сел и городов, как правило, были оснащены киноустановками. К 1962 г. на Ставрополье были построены кинотеатры с вместимостью от 700 до 1200 зрителей, например, «Мир»- в Невинномысске, “Экран» и «Родина» - в Ставрополе. Это вызвало зрительский ажиотаж. Средний показатель посещаемости кинотеатров в 1968 г. достигал 25 посещений в год на человека, что сравнительно выше среднего советского показателя [6]. К просмотру зрителям предлагали фрильмы, основанные на основных постулатах коммунистической идеологии.

Новой и активно набирающей популярность формой проведения досуга были кружки и клубы по интересам. Например, «существовал клуб деловых встреч, где обсуждались многочисленные вопросы с юридической направленностью» [2, c. 2]. Дети посещали кружки, такие как фотокружок, кружок выжигания, театральные. На базе ставропольского драматического театра организовывались тематические мероприятия для молодежи по возрастным категориям, где обучали актерскому мастерству, пониманию смыслового содержания спектаклей - «языку театра». Как городские, так и сельские жители края свой досуг проводили в избах-читальнях. В них проводились тематические мероприятия различных форматов читались доклады, лекции, выступали агитационные бригады и др.

На стремительное развитие городов Ставропольского края влияние оказали природные условия, а именно богатство недр минеральными источниками. Первым в истории нашего государства курортом стал район Кавказских Минеральных Вод, который привлекал туристов из всей страны, но был недостаточно благоустроен для их приема. Поэтому во второй половине XX в. руководство СССР и местные власти были заинтересованы в развитии рекреационных возможностей данного региона, так как наличие курорта оказывало влияние, как на экономическую сферу так и на культурную и социальную жизнь края и государства. Начиная с 1955 г. разрабатываются проекты по планированию и строительству курортных городов. Так, например, город Минеральные Воды развивался как железнодорожный узел, промышленный, административный и культурный центр Минераловодского района. Здесь планировалось за счет увеличения территории города в южном и восточном направлениях осуществить постройку 2-х - 3-х этажными (75\%) и индивидуальными домами $(25 \%)[5$, с. 3]. В центре города решено было организовать главную площадь на проспекте Карла Маркса. Планировалось сохранить существующую уличную сеть и проложить новые магистрали. Проект предусматривал также увеличение площади зеленых насаждений до 110 га. Прежде всего, сделать это за счет насаждения городских садов, скверов и бульваров в жилых районах. Озеленить санитарные зоны разрыва между промышленными пред- приятиями и спальными частями города [5, с. 4] Особое внимание, уделялось увеличению количества городского транспорта, хотя основным видом по-прежнему оставался автобус. Проект предусматривал реконструкцию и прокладки новых сетей водо-, газо- и энергоснабжения города [5, с. 5]. Подобные проекты по благоустройству городов были разработаны и в городах Ессентуки, Пятигорск, Кисловодск.

В проектах главным пунктом было увеличение количества, расширение и благоустройство имеющихся лечебно-профилактических центров. Под руководством ведомственных министерств совместно с краевой властью, повсеместно возводились санитарно-курортные учреждения. В городах группы Кавминвод проводилось активное озеленение городов, строились кинотеатры, концертные залы и другие заведения проведения досуга горожан и туристов. В Кисловодске и Пятигорске, особой популярностью в это время, стали пользоваться построены подвесные канатные дороги на горы Машук и Большое Седло. В Ессентуках был расширен городской парк до 70 гектар, построены спортивные базы во всех районах города. В середине 1960-х гг. толчок к развитию получила лечебная и материально- техническая база в детских санаториях и санитарно-оздоровительных учреждениях. Нельзя не отметить и проявившуюся тенденцию полицентризма на территории курортных городов Северного Кавказа. Это поспособствовало одному из старейших город-курортов - Пятигорску - стать неофициальным административным центром района Кавказских Минеральных Вод. В нем сконцентрировалась обширная научная база, которая позволила городу наряду с краевым центром Ставрополем стать вузовским и культурным центром. Одновременно стремительными темпами развивались промышленные предприятия города. С одной стороны, это оказало негативное влияние на состояние курортного региона и качество предоставляемых услуг. Но с другой, привело к увеличению численности населения, так к 1960 г. на территории курортного региона проживала треть населения края. Попытки местной курортной власти ограничить промышленное строительство на территории курортных зон и проведение мероприятий по охране имеющихся ресурсов, часто приводили к разногласию с краевым руководством. Но функционирование промышленные предприятия было необходимо для обеспечения полной занятости жителей городов- курортов. Согласно указу Совета Министров в 1975 г. на территории Кавказских Минеральных Вод функционировали 2 курортные зоны, а к 1986 г. более 100 санаториев [1, с. 170].

Подводя итог, вышесказанному отметим: по сравнению с общероссийскими темпами роста городов и городского населения, Ставрополье регион с поздней урбанизацией. В силу своей сельскохозяйственной специфики Ставропольский край в 1960-е гг. только стал на путь модернизации и урбанизации, которые повлекли за собой социокультурные изменения. Города стали централи культурного, научного и промышленно развития. Отток населения сел и деревень в го- 
родской ареал происходил за счет увеличения количества предприятий различных отраслей промышленности. Сельская молодежь в городах осваивала не только новые профессии, обучаясь в высших и средних учебных заведениях, но и городской образ жизни. Поэтому жизнь в сельской местности стала все больше приобретать городские черты.

\section{Источники и литература}

1. Булыгина Т. А. Некоторые тенденции социокультурного, хозяйственного и политического развития Северного Кавказа в конце 1960-х - начале 1980-х годов// Наука. Инновации. Технологии. 2013. №2. С. 161-172.

2. Государственный архив Ставропольского края (далее - ГАСК). Ф. 3844. ОП. 1. Д. 9

3. ГАСК. Ф.3844. Оп. 1. Д. 11.

4. ГАСК. Ф.3844. Оп. 1. Д. 12

5. ГАСК. Ф.3844. ОП. 1. Д. 13

6. ГАСК. Ф.4127. ОП. 1. Д. 941.

7. История городов и сел Ставрополья / ред. Д. В. Кочура. Ставрополь, 2001. 752 С.

8. Итоги Всесоюзной переписи населения 1959 года РСФСР / Центр. стат. упр. при Совете Министров СССР. М.: Госстатиздат, 1963. $456 \mathrm{c}$

9. Итоги Всесоюзной переписи населения 1970 года РСФСР / ЦСУ при Совете Министров СССР. М.: Статистика, 1972. $576 \mathrm{c}$.

10. Комлев Н. Г. Словарь иностранных слов. М.: Эксмо, 2006. 669 с

11. Комлев Н. Г. Словарь иностранных слов. М.: Эксмо, 2006. 669 с.

12. Край наш Ставрополье. Очерки истории. Ставрополь: Шат- гора, 1999. 528 с

13. Лаппо Г.М. Города на пути в будущее. М.: Мысль, 1987. 237 с.

14. Ногина Е.В. Социокультурное развитие городского населения Ставрополья в 1920-1930 годы: опыт исторического исследования : диссертация ... канд. ист. наук. Ставрополь, 2004. 264 c. URL: https://dlib.rsl.ru/ viewer/01002740028\#?page=1 (Дата обращения: 05.11.2018)

15. Ракчеев В.Н. Урбанизация и особенности расселения на Кубани и Ставрополье в 1930-1950-е гг. // Исторические науки, этнология и археология. 2014. №2. С.84- 88.

16. Сенявский А.С. Урбанизация России в XX веке: Роль в историческом процессе. М.: Наука, 2003. 288 с

\section{References}

1. Bulygina T. A. Nekotorye tendentsii sotsiokul'turnogo, khozyaistvennogo i politicheskogo razvitiya Severnogo Kavkaza $\checkmark$ kontse 1960-kh - nachale 1980-kh godov (Some Tendencies of Socio-Cultural, Economic and Political Development of the North Caucasus in the Late 1960s - Early 1980s) // Nauka. Innovatsii. Tekhnologii. 2013. No. 2. P.161-172. (In Russian).

2. State Archive of the Stavropol Krai. F. 3844. Inv. 1. D. 9. (In Russian).

3. GASK. F.3844. Inv. 1. D. 11. (In Russian).

4. GASK. F.3844. Inv. 1. D. 12. (In Russian).

5. GASK. F.3844. Inv. 1. D. 13. (In Russian).

6. GASK. F.4127. Inv. 1. D. 941. (In Russian)

7. Istoriya gorodov i sel Stavropol'ya (History of Towns and Villages of Stavropol) / ed by D. V. Kochura. Stavropol': SSU publ., 2001. 752 p. (In Russian).

8. Itogi Vsesoyuznoi perepisi naseleniya 1959 goda RSFSR (Results of the All-Union Population Census of 1959 RSFSR). Moscow: Gosstatizdat, 1963. 456 p. (In Russian).

9. Itogi Vsesoyuznoi perepisi naseleniya 1970 goda RSFSR (Results of the All-Union Population Census of 1970 RSFSR). Moscow: Statistika, 1972. 576 p. (In Russian).

10. Komlev N. G. Slovar' inostrannykh slov (Dictionary of Foreign Words). Moscow: Eksmo, 2006. 669 p. (In Russian).

11. Krai nash Stavropol'e. Ocherki istorii (Stavropol is Our Krai. Essays on History). Stavropol': Shat- gora, 1999. 528 p (In Russian).

12. Lappo G. M. Goroda na puti v budushchee (Cities on the Way to the Future). Moscow: Mysl', 1987. 237 p. (In Russian)

13. Nogina E. V. Sociokul'turnoe razvitie gorodskogo naseleniya Stavropol'ya v 1920-1930 gody: opyt istoricheskogo issledovaniya (Socio-Cultural Development of the Urban Population of Stavropol in 1920-1930: the Experience of Historical Research): thesis. Stavropol', 2004. 264 p. URL: https://dlib.rsl.ru/viewer/01002740028\#?page=1 (Accessed: 05.11.2018). (In Russian).

14. Rakcheev V. N. Urbanizatsiya i osobennosti rasseleniya na Kubani i Stavropol'e v 1930-1950-e gg. (Urbanization and Features of Resettlement in the Kuban and Stavropol in the 1930s-1950s) // Istoricheskie nauki, etnologiya i arkheologiya. 2014. No.2. P.84-88. (In Russian).

15. Senyavskii A. S. Urbanizatsiya Rossii v KhKh veke: Rol' $v$ istoricheskom protsesse (The Urbanization of Russia in the Twentieth Century: The Role in the Historical Process). Moscow: Nauka, 2003. 288 p. (In Russian).

\section{Сведения об авторе}

Пыркина Елена Игоревна - аспирант кафедры истории России гуманитарного института Северо-Кавказского федерального университета (Ставрополь) / alena.pyrkina@yandex.ru

Information about the author

Elena Pyrkina - postgraduate student, Chair of Russian History, Institute of Humanities, North Caucasus Federal University (Stavropol) / alena.pyrkina@yandex.ru 